\title{
¿HA PASADO DE MODA EL NOVIAZGO?
}

María Pliego Ballesteros

\section{RESUMEN}

LAS IDEAS CLARAS SOBRE EL SIGNIFICADO DEL NOVIAZGO, DETERMINAN las actitudes convenientes en esta hermosa etapa de la vida que se va convirtiendo en la base de un matrimonio felizy una adecuada vida familiar.

En este trabajo se analizan una serie de virtudes: prudencia, lealtad, templanza, honestidad, sobridad, generosidad, responsabilidad, amistad y justicia para alentara las personas a esforzarse y cultivarlas en este peńodo.

\section{ABSTRACT}

The clearideas on what engagementis, guide the properattitudes that this beautiful stage of life has, which becomes the basis for a happy marriage and an upright family life.

A series of virtues: prudence, loyalty, temperance, honesty, soberness, generosity, responsibility, friendship and justice are analyzed to encourage people to fightin orderto reach them during this period.

\section{INTRODUCCIÓN}

ES NOTABLE EL DETERIORO EDUCATIVO QUE HOY SUFREN MUCHAS FAMIlias. Se ha vuelto lugar común en la conversación entre adultos, la queja contra la juventud por la falta de principiosy la no observancia de las normas sociales de convivencia. No es novedad. La tendencia histónica de la generación madura, acusa una actitud repetitiva de cierto rechazo e incomprensión hacia losjóvenes - y más, hacia los adolescentes- - Lo curioso es que la mayoría de dichas quejas, permanecen en la esterilidad porfalta de visión, de responsabilidad, 
de decisión para adoptar una actitud positiva, reflexiva y actuante, de poner los medios adecuados para no formar parte consciente 0 inconsciente del problema, sino de la solución.

Cuántos padres de familia, maestros, gobemantes, profesionales de la comunicación, evaden la problemática, pensando que es tan grande, que su pobre esfuerzo se diluirá en la nada. Impotentes y desarmados antes de iniciarla lucha positiva poreducary educarse, se suman a la comiente destructora, en vez de colocar su grano de arena, la fuerza de uno», para ir «ahogando el mal en abundancia de bien».

El objetivo de la presente colaboración es inyectar entusiasmo - fundamentado racionalmente- en el ánimo de todo adulto, consciente del papel educativo que juega en toda sociedad, para poner manos a la obra. Somos comesponsables del mencionado deterioro educativo. Todos formamos parte de una familia en cuyo seno se fragua la solidaridad o el aislamiento egoísta que produce frutos tan amargos: soledad, angustia, injusticia y zafiedad o vulgaridad.

Escribir sobre este acuciante problema, no basta. Tanto el lector como yo hemos de luchar por hacervida las propuestas intelectuales. Pero también es verdad que los cambios de actitud tienen su origen en un conocimiento profundo del qué, el porqué y el para qué de ese viraje en nuestro modusvivendi.

\section{IDEAS CLARASY CONGRUENCIA DE VIDA}

Si separamos lo intelectivo de lo vital, no hay eficacia y menos eficiencia. Ambos son indispensables. La inteligencia sin la voluntad se convierte en utopía; $\mathrm{y}$ viceversa, la voluntad sin la inteligencia no actúa, se paraliza.

He elegido la educación de las virtudes durante una época clave: el noviazgo. Constato día a día la desorientación reinante en lo que analógicamente podríamos llamar łos cimientos del matrimonio». Si de construir se trata, los buenos pilotes pueden sostener edificios de más de cicuenta pisos. Ojalá todos los novios comenzaran el matri- 
monio con la ilusión de llegara sus bodas de oro. Habrá algunos que lo vean como un sueño imposible: no han asistido jamás a ninguna ceremonia de bodas de plata..., mucho menos de oro. No es un sueño imposible, sino un ideal realizable, si Dios concede una larga vida. La gracia del matrimonio hace posible lo que con las solas fuerzas humanas parece irrealizable. Pero hay que cimentar bien los fundamentos.

\section{¿POR QUÉ VIRTUDES EN VEZ DE VALORES?}

Llevamos décadas utilizando el término valor como sinónimo de virtud, porpura ignorancia o porcomodidad, para evitarpolémicas de tipo ético-religioso. La confusión se propicia al considerar que tanto las virtudes como los valores perfeccionan al ser humano. Es verdad. Pero si nos adentramos en la perspectiva de la filosofía realista, entendemos que el valor está íntimamente ligado al ser: todo lo que es, por el hecho de ser, vale. Los trascendentales del ser son, a la vez, valores: unidad, verdad, bondad y belleza. En cambio, las virtudes son accidentes cualitativos sólo imputables a la persona porque requieren de la inteligencia y de la voluntad libre para realizarlas 2 .

La virtud es un hábito operativo o disposición permanente que mueve a obrar el bien y a evitar el mal. Puede tener su origen en el mismo sujeto (virtudes adquinidas) o puede serinfundido de manera gratuita por Dios (virtudes infusas).

Ciertamente esta primera clasificación en virtudes adquiridas o infusas, nos remite a la Teología: la fe, la esperanza y la caridad (virtudes teologales), infundidas en nuestra alma con las aguas del bautismo ${ }^{3}$. Pero quedan multitud de virtudes al alcance de cualquier ser humano - aun no bautizado - que una educación esmerada, con base en el ejercicio de la inteligencia y de la voluntad, puede promovery fomentar. Se trata de que la persona, para adquirir una virtud, se ejercite libremente en la repetición de actos propios de tal virtud hasta que, en las situaciones que requieran de ella, responda adecuadamente, con facilidad, prontitud y hasta agrado por haberla incorporado ya a su personalidad. 
Un ejemplo clásico es la virtud del orden. Nuestros padres - si tuvimos la dicha de naceren uno de esos hogares łuminososy alegres st que propician el desarrollo de la autoestima, de la dignidad propia del ser humano- nos hicieron el gran servicio de colocamos una especie de plataforma acostumbrándonos desde recién nacidos (y aun antes, durante el embarazo) a tener orden en los horanios para comery dormir, orden en las costumbres higiénicas de nuestro aseo corporal y orden en proporcionamos un ambiente limpio y de buen gusto.

El orden puede ser exterior - un lugar (yun tiempo) para cada cosa y cada cosa en su lugar - o intenior - en el pensamiento lógico y en los afectos-. Cuando el niño empieza a ser consciente de sus actos, puede pedírsele, con una sonnisa firme, que levante los juguetes utilizados, que deposite la ropa sucia en su lugar, que respete el orden de cada miembro de la familia y - si lo hay - del servicio doméstico. Esto equivale a ino llevando por un plano inclinado en el que - como en todo - ha de graduarse la dificultad y motivando el esfuerzo constante por conquistarla virtud. Son naturales los altibajos, sobre todo en la adolescencia, puesto que el orden integral de la tercera infancia, se derrumba al entrar en juego todos los cambios biopsicosociales que inician en la pubertad. Sin embargo, lo bien sembrado permanece: la repetición de actos de orden que había consolidado la virtud, parece desaparecerporla repetición de actos contrarios y la omisión de actos ordenados, pero se recobran si se les ayuda a lucharcontra el desorden, que en el fondo les avergüenza y disgusta. Con paciencia, con motivos trascendentes, con el buen ejemplo y con el tiempo, pueden readquirirel hábito del orden, base de toda virtud.

Las variantes caractereológicas son muy de tomaren cuenta. Los no emotivosy secundarios tienden a sermás ordenados. Algunos se vuelven nígidos, meticulosos y perfeccionistas: se pasan de la raya, y este exceso desvirtúa el fin porque llegan a faltar en la virtud por excelencia, que es el Amor recto y ordenado. En cambio habrá que ayudarles más en la comprensión y en la generosidad, sobre todo en saberperdonar. 
Aunque me he alargado en la ejemplificación de una virtud, por sertan básica, considero que ha valido la pena.

\section{EL NOVIAZGO}

Ideasclaras: dado el erotismo reinante, la confusión aumenta sus víctimas, parapetada en el mutismo de quienes debenian hablary - por ignorancia o pasividad - provocan lo de que un ciego guíea otrociego yamboscaigan en el precipicio.

Todo educador - padres, maestros hermanos mayores, amigos, médicos, etcétera - debeńa hacerse uno con los otros para que cada quien, en su ámbito, legueantesque las imágenes nocivas, los chistes que ridiculizan el verdadero amoro el cinismo de quienes empujan a los amoníos ilícitos y degradantes. №! El noviazgo no ha pasado de moda: es un tiempo de preparación para un posible matrimonio, en el que la prudencia, la lealtad, la templanza y la sinceridad, deben ejercitarse para resistir al embate de sus contranios.

La prudencia en el noviazgo consiste, en primer lugar, en tenera la vista el objetivo: un posible matrimonio. En segundo lugar, elegir los medios que mejor puedan conducimos a alcanzanlo. O sea que si uno de los interesados - hombre y mujer, naturalmente- no pensara en casarse, estanía cometiendo no sólo una imprudencia, sino una injusticia con su pareja. Por desgracia esto es más frecuente de lo que imaginan los interesados. Pueden existir fuerzas ocultas de malformaciones de la personalidad, que vean el noviazgo como un modo de demostrar - ante sí mismos y ante los demás- que se es una persona nomal capaz de inspirar amor - o más bien deseo- a alguien del sexo complementario. Conste que aclaro esto porque los conflictos de los homosexuales no se dilucidan sólo con el psiquiatra, sino que van ganando terreno y, so pretexto de exigircomprensión y respeto, desnudan impúdicamente su intimidad herida, en la búsqueda de algo que les asegure su identidad sexual.

Otro motivo más o menos oculto, que puede o no originarse del anterior, es la actitud gregaria de hacer lo que todo mundo hace, 
para no sentirse marginado o «icho raro». Curiosamente es en la adolescencia, al tratar de distinguirse de los demás, cuando la persona clama con todas las veras del alma: «Soy diferente!, no me compares con nadiel»: Pero la reputación ante los compañeros de la misma edad, leva a asumir sus mismas deficiencias e insegunidades.

Hay que afrontarel problema y potenciarjustamente las diferencias individuales, realizando un llamado al propio respeto y al de la pareja para no jugar con fuego: es una falta de lealtad hacer creer al otro lo que no hay en mí. Utilizar a un sujeto para fines personales es cosificarlo y, así, manipularlo: una cosa no tiene personalidad, ni sentimientos, ni libertad, ni inteligencia para descubrir el engaño.

La lealtad, en cambio, da la cara: piensa prudentemente antes de dar el sí a un compromiso que exige exclusividad y cumple con él mientras vaya viento en popa la relación, o rompe el noviazgo al valorar que la otra persona no es la indicada para entregarle toda la vida en un proyecto común.

Porsu lado, la templanza ha de ejercitarse - y como están hoy las cosas, jen grado heroico! - partiendo del natural atractivo entre los dos sexos. Los extremos en este caso, se dan en abundancia: 0 el temor alarmista ante el sofisma de falsa generalización de personas timoratas y escrupulosas que ven el mal donde no lo hay, o la ingenuidad que lleva a bajar la guardia, pensando en que no existe ningún peligro, como si tratáramos con personas angelicalesy no humanas. Es cierto que el controlar, regular, dirigir los placeres de los sentidos depende mucho del temperamento, del tiempo que lleve la relación y del que vaya a durar hasta llegar al término del matrimonio; de las circunstancias que los rodeen - compañía o soledad, iluminación, media luz u oscuridad-, de los temas concretos que interese profundizar, en vez de dejarla mente suelta, vagando en el acaso.

Emma Godoy comparaba el noviazgo con una carrera universitaria, pues implica un plan de estudios que hay que cursary, luego, sujetarse a una serie de exámenes mutuos que se han de superarcon las mejores calificaciones posibles. 
El plan deestudiospuede configurarse con los ocho valores - que se analizarán en seguida - necesarios para integrar una personalidad madura. La calificación no depende tanto de la excelencia de las virtudes requeridas para realizar cada valor, sino más bien de dos factores clave en la relación del noviazgo: la capacidad de cambio en el otro y la propia capacidad de aguante. La perfección es imposible encontrarla en sujetos meramente humanos. Luego, partiendo de la realidad de que no somos ni dioses ni diosas, fabriquémonos un termómetro capaz de medirfielmente dichas capacidades de cambioy aguante.

Por ejemplo, habrá quien tolere más una manifestación de inmadurez afectiva - como llorar por una nadeńa - y se muestre intolerante hacia un mal hábito de higiene; o viceversa: no preste atención al uso de la pasta de dientes pero reviente ante un lloriqueo por la muerte de una mascota.

1. VALORESECONÓMICOS. Las virtudes claves son la sobriedad y lagenerosidad.

La primera se opone al despilfarro y a la avaricia. Hay que preguntarse - y responderse mediante la observación y el diálogo- qué tanto nos hemos dejado llevarpor el consumismo, cuántas necesidades creadas nos conminan a gastar imeflexivamente; cómo está nuestra tendencia hacia el lujo, la comodidad, el capricho, la vanidad; qué tanto cuidamos o descuidamos los objetos de uso propio y común; cómo administramos nuestros ingresos, etcétera.

La generosidad se opone a la ambición exagerada y a la pusilanimidad. Habnía que examinar, verbigracia, cómo compartimos los bienes materiales con los más necesitados; si evitamos la comparación y los subsecuentes complejos de supenioridad o de inferionidad; si tratamos a los demás por lo que tienen y no por lo que son; si nuestra pequeñez de ánimo nos impide emprendercosas mayores o nos intimida ante los ideales o ante las pequeñas, medianas o grandes empresas. 
Parece increíble que un porcentaje significativo de divorcios, ocuran pormotivos económicos. Si desde el noviazgo hay ocultamientos en torno a los ingresos de cada uno, ¿qué se espera para después? Hay adultos que malaconsejan en este renglón porque les ha ido mal en la feria, y losjóvenes pueden admitir prejuicios y desconfiar del uso de los bienes que van a ser comunes. Al casarse ya no es nada «uyo»0 «mío» sino «uestro». El matrimonio implica compartirlo TODO. Pero siempre resulta que uno de los dos es mejor administradorque el otro, y que uno de los dos tiene mayorvisión del futuro para cuidarel patrimonio de los hijos. Precisamente por eso hay que hablarmuy claro y preveniren vez de remediar.

2. VALORESFÍSICOS. La templanza modera la inclinación al placer, dentro de su justo límite. Hay personas que gozan y agradecen el don de la vida; cuidan su salud y la de los demás; son moderados en el comer, en el beber, etcétera. En cambio, otras son incapaces de fijarun límite a sus gustos y caprichos: huyen del dolora como dé lugar, su sensualidad las convierte en egocéntricas, incapaces de amar y llegan a estar imposibilitadas para pensar en los demás. Con relación a alguna película o a algún acontecimiento, valdnáa la pena preguntar. ¿Qué sentido tiene el dolor, la vida, la muerte para ti? ¿Qué piensas del aborto, la eutanasia y el «uicidio asistido»?

Éstos son temas trascendentales, pero los roces se dan en lo cotidiano y la vida se puede tomarimposible por las manías de uno, los desórdenes de la otra, las exigencias incomprensibles de ambos, etcétera. Si no existe una recta disposición para ceder en algunos casos, o concederen otros, dar gusto mutuamente, aprender a comer con otro estilo de cocinary sujetarse amablemente a un nuevo orden de vida, es posible que aún no haya madurez en el amor, en el don de sí y el egocentrismo niñoide haga trizas una relación que no puede ni debe conduciral matrimonio.

3. LOSVALORESSOCIALESrequieren especialmente de la virtud 
de la responsabilidad, que implica solidanidad con los demás. Quien sea capaz de responderante la sociedad del buen uso que haya hecho de sus potencialidades personales, o se disponga a trabajar en senio para mejor servira los demás, sabrá diferenciar al imesponsable que entierra sustalentosen vez de ponenlos a rendir, o que no responde positivamente ante los requenimientos justos de la sociedad.

También existen normas sociales de cortesía que debemos observar, pues de lo contranio la ley de la selva operanía. Por ejemplo: ¿Cómo conduce el coche y trata a los peatones?, ¿cómo utiliza el claxon?, ctiene consideración con los que están domidos?, ¿se disculpa si no puede asistir a alguna reunión o compromiso?, ¿cómo se comporta en la mesa y en eljuego?

Responder por los propios actos se aleja de la actitud de quien, por costumbre, tiende a escudarse o incluso a inculpar a otros, sin aceptarla parte que le comespondenía a sí mismo.

También es interesante observar el interés político y el comportamiento ciudadano. La afiliación partidista contraria, suele ser causa hasta de divorcios; el desinterés por la Historia y el devenir de los núcleos sociales, puede abrir una brecha interpersonal, si a la contraparte le apasiona este tema, al grado de comprometer su vida por una causa social.

4. LOSVALORESAFECTIVOSson importantísimos. La madurez emocional puede concretarse en la virtud de la amistad: querer el bien del otro (amorde benevolencia) - aun por encima del bien propiorequiere grandeza de ánimo. La capacidad de salirde sí mismo para donarse al otro, va desde prestar auténtica atención a lo que en términos generales no seńa del propio interés, hasta la afabilidad o trato agradable, que se aleja de los extremos de la aspereza y de la adulación.

Algunos piensan que el amor del noviazgo es totalmente diferente a la amistad y no es así. Cabe preguntarse: ¿Me podńa pasarTODA la vida platicando con él o ella? Es cierto que el atractivo sexual especifica la diferencia entre la pura amistad y el noviazgo, pero cuán 
importante se torna cuando dicha atracción disminuye hasta casi quedarexcluida.

También es importante interactuar con el grupo de amistades ya constituido, de cada uno por separado. Quizá alguna o alguno de ellos deba ser sacrificado, porno serdel agrado o porserdemasiado agradable a la pareja: elegir es renunciar. En cambio, no sería justo pretender que se renuncie al total de las amistades frecuentadas antes del compromiso y la cierta exclusividad que supone el noviazgo.

Otro punto interesante es el que compete a la virtud de la castidad. Una adolescente de tercero de secundaria me preguntó: «Cuándo puedo tener relaciones sexuales?» Mi respuesta fue: «Cuando te cases» Su expresión desangelada me apenó y me dio mucho en qué pensar.

5. LOSVALORESINTELECTUALES se cifran en el amor a la Verdad, como objeto de nuestro entendimiento, y en la virtud de la estudiosidad. Es de suma importancia profundizaren conceptos como amor, libertad, persona, dignidad, matrimonio, familia... La manipulación semántica destroza hasta lo más bello y sagrado.

Si un novio tiene inquietudes intelectuales, selecciona prudentemente sus lecturas, investiga en fuentes confiables sus dudas, ama el estudio - no sólo de su especialidad sino atendiendo a una amplia gama de intereses culturales- y su novia se muestra perezosa, indolente, o sólo cuniosilla, pero inconsistente, es fácil predecir que ese noviazgo o incluso ese matrimonio no llegue a buen fin.

Mas el peligro actualmente, come en sentido contranio. La mujer se prepara y en varios casos aventaja al hombre por su dedicación y esfuerzo.

Cada vez se le abren más las puertas para estudios de posgrado, para participar en eventosy concursos nacionales e intemacionales. Es posible que gane más que su novio o su marido. Ello ocasiona rupturas frecuentes, por deficiencias de las propias mujeres que maleducan»a sus hijos en un machismo injusto, de funestas conse- 
cuencias. También el peligro asecha a las universitarias deficientemente educadas en la dignidad, belleza y trascendencia de la maternidad y de las labores del hogar, y que luego se niegan a poner entre paréntesis, por algún tiempo, mientras dure la crianza, su sapiencia y prestigio profesional. Poreso, es importante sondear estos aspectos. Para el varón: ¿Te gustańa seguir trabajando?, çhasta cuándo?Para la mujer: ¿Qué hańas si yo te superara en los ingresos para nuestra familia?...

6. LOSVALORESESTÉTICOS exigen mucha prudencia para no perder su jerarquía respecto a los valores morales. La postura del arte porel arte»no es sostenible. El argumento principal descansa en la esencia del arte versusla esencia de la moral. El primero busca el bien de la obra; la segunda, el bien de la persona. Hay multitud de ocasiones, durante el noviazgo, que se prestan para saber si la pareja está en consonancia o no con esta postura: el mal llamado «cine de arte», teatro, espectáculos, videos, etcétera, que esconden o exhiben lo pornográfico, o lo que desorienta porque tergiversa el bien y el mal, llamándole sbien»a lo intrínsecamente malvado, o por lo menos presentándolo como fácil, simpático y divertido, y ridiculizando la bondad, hasta hacerla repulsiva. Eso, porlo que corresponde al espectador pasivo. Pero también quien posea el don de la creatividad artística, tiene que formar bien su conciencia, para no ofrecer nada que pueda manchar con su lectura, su audición o su visión, tanto a un viejo como a un niño.

Además, el gozo de la belleza natural y artística, posee un valor integrador de la personalidad, porque tiene que vercon toda ella. $\mathrm{Si}$ no hay gustos afines, qué triste vejez se espera. En cambio, si se comparten gustos e intereses estéticos, cómo se disfruta la compañía de un ser querido que vibra ante la magnificencia de la belleza.

7. LOSVALORESMORALESpropician el ejercicio de todas las virtudes humanas. El latín vir significa fuerza, porlo que no hay virtud 
moral que se nos regale. Conquistarlas implica hacemos violencia, porque el desorden y la tendencia a la comodidad, nos tiran hacia abajo. Y es necesario ejercitamos, no perder forma para conquistar las cumbres del espíritu. Además, la justicia - que significa la voluntad firme de darle a cada cual lo que le pertenece- - nos orienta desde a obedecerla ley divina y las leyes humanas que procuren el bien común de la sociedad, hasta la equidad que llega a suavizar la estricta justicia, tomando en cuenta otras consideraciones superiores que nos acercan a la caridad y a la misericordia. Cuán injusta es la justicia a rajatabla que no considera las diferencias individuales, las circunstancias que pueden atenuar o agravar un mal cometido, y la disposición al arrepentimiento y la reparación del daño causado.

Ésta es una materia delicada que exige mucho estudio de ambos noviosy después esposos, porque no termina nunca. He escrito estudio serio y profundo, en fuentes limpias. Pero en ocasiones, la casuística es tan complicada que vale la pena acudirde motu propio al consejo de especialistas doctosy de vida recta, para que nos orienten en el camino que vamos recomiendo. Sin embargo, hay un principio rector de validez perenne: a la persona no se le juzga, se le ayuda, se le educa, se le ofrecen alternativas... pero al mal se le llama porsu nombre y no se le tolera.

8. LOSVALORESRELIGIOSOSnos llevan al plano sobrenatural, a la región más delicada de nuestra conciencia, al santuario de nuestra relación íntima con la Divinidad. La virtud de la religiosidad, con la fe, esperanza y caridad tocan con la máxima profundidad al sentido de la vida, de la muerte y del dolor. Se debe observary retroalimentar con delicadeza, si hay congruencia entre lo que se cree y cómo se vive; y si hay apertura de mente y de voluntad para profundizar la doctrina y vivir mejor las normas de piedad en el trato con lo sacro. Aun siendo de la misma religión, puede haberroces, incoherencias o intentos de violación en lo que sólo compete al alma y a Dios. Naturalmente esto aumenta si no se profesa la misma religión. Se debe 
prever, desde el noviazgo, el momento en que los hijos se cuestionen si es papá o es mamá quien está en la Verdad. Cuánto indiferentismo religioso se evitańa si tomáramos más en senio la relación de nuestro destino eterno, la forma de enfocary vivir la existencia cotidiana.

Ojalá estas reflexiones cumplan su cometido: colaborar, de alguna manera, en que las bases del matrimonio y de la familia se construyan sólidamente en el bello lapso del noviazgo.

\section{REFERENCIAS BIBLIOGRÁFICAS}

${ }^{1}$ Cfr. ESCRIVÁ DE BALAGUER, Josemańa., Amigos de Dios., Editorial Rialp., Madrid., 1977.

${ }^{2}$ Cfr. PLEGO BALESTEROS, Manía., Losvaloresy la familia., Editorial Minos., México., 1996.

${ }^{3}$ Cfr. FARÍA, Rafael., Curso superior dereligión., Editorial Voluntad., Bogotá., 1950.

${ }^{4}$ ESCRIVÁ DE BALAGUER, Josemaría., Es Cristo que pasa., Editorial Rialp., Madrid., 1974., p.73 